Review Article

\title{
The Effectiveness of Interventions in Improving Hand Hygiene Compliance: A Meta-Analysis and Logic Model
}

\author{
Mohammad Hossein Kaveh $\left(\mathbb{D},{ }^{1}\right.$ Mohadeseh Motamed-Jahromi ${ }^{D}{ }^{2}$ \\ and Soheil Hassanipour $\mathbb{D}^{3}$ \\ ${ }^{1}$ Research Center for Health Sciences, Institute of Health, Department of Health Promotion, School of Health, \\ Shiraz University of Medical Sciences, Shiraz, Iran \\ ${ }^{2}$ Department of Health Promotion, School of Health, Shiraz University of Medical Sciences, Shiraz, Iran \\ ${ }^{3}$ Cardiovascular Diseases Research Center, Department of Cardiology, Heshmat Hospital, School of Medicine, \\ Guilan University of Medical Sciences, Rasht, Iran \\ Correspondence should be addressed to Mohadeseh Motamed-Jahromi; mohadesehmotamed@yahoo.com
}

Received 4 August 2020; Revised 12 March 2021; Accepted 30 June 2021; Published 19 July 2021

Academic Editor: Massimo Girardis

Copyright (c) 2021 Mohammad Hossein Kaveh et al. This is an open access article distributed under the Creative Commons Attribution License, which permits unrestricted use, distribution, and reproduction in any medium, provided the original work is properly cited.

\begin{abstract}
Background. Despite the availability of various guidelines, rules, and strategies, hand hygiene adherence rates among healthcare workers are reported significantly lower than expected. The aim of this meta-analysis is to determine the most effective interventions to improve hand hygiene and to develop a logic model based on the characteristics of the most effective interventions. Methods. A literature search was conducted on PubMed, ProQuest, Web of Knowledge, Scopus, Cochrane Library, and ScienceDirect databases up to December 21, 2019, with no time limit. Randomized clinical trials which had designed interventions to improve hand hygiene were reviewed. Data were extracted independently by two authors. All statistical analyses were performed using Comprehensive Meta-Analysis (CMA) software (version 2.0). A random-effects model was used to estimate odds ratios. Results. Although 14 studies were initially reviewed, only 12 studies entered the meta-analysis, since they had identified percentage rates of hand hygiene compliance. The most effective intervention (odds ratio 18.4, 95\% CI (13.6-24.8)) was a multilevel strategy that influenced the determinants of hand hygiene behavior at individual, interpersonal, and organizational levels. Following this, a theory-driven logic model was mapped out to promote hand hygiene, based on situational analysis. Conclusion. This study suggests that designing integrated interventions based on a multilevel socioecological approach has the greatest potential to improve hand hygiene compliance in healthcare workers. The logical model proposed in this study can thus provide a useful guide for designing and conducting future experimental research.
\end{abstract}

\section{Introduction}

Hospital infections can pose significant threats to healthcare systems, affecting the rates of illness, mortality, and length of in-hospital stay, while also increasing healthcare costs [1-5]. A global survey conducted by the World Health Organization (WHO) estimates $7 \%-12 \%$ of hospitalized patients suffered from nosocomial infection [6]. It is noteworthy that the relationship between improving hand hygiene and reducing nosocomial infection has been indicated for more than 150 years, and hand hygiene has been widely accepted as the cornerstone of infection prevention and control programs [7-9]. However, the presence of frequent nosocomial infections indicates poor adherence to hand hygiene [10]. According to research, the rate of adherence to hand hygiene among healthcare providers has been estimated at $20-40 \%$ [11].

The reasons for poor hand hygiene adherence may include lack of facilities, lack of staffing, busy workplaces, skin irritation, lack of role models, and disregard for instructions $[1,12-14]$. Therefore, the strategies for improving hand hygiene adherence should focus on multiple approaches 
$[15,16]$. In this regard, the World Health Organization has provided multiple strategies, including system change, education and training, observation and feedback, hospital reminders, and a safe hospital environment [17].

Previous studies have also employed multifaceted strategies, which have included management and procurement support, education and training, reminders, monitoring, performance feedback [18], empowerment, environmental reconstruction, encouragement [19] and goal setting, reward incentives, and accountability [20]. However, these strategies have had multiple design limitations, which have made it difficult to judge their overall effects. For example, multiple factors influencing adherence to hand hygiene were not initially identified within these studies, and therefore strategies were not systematically tailored based on situational analysis. In addition, most strategies targeted only short-term outcomes.

The success of a multifaceted intervention depends on the success of a complete simultaneous sequence of influencing factors [21]. Accordingly, it is necessary to determine the most effective strategy and its influencing components to increase adherence to hand hygiene. Likewise, it is important to draw a logical model to represent the relationships between a program's components and intended effects. Logical models are implicit maps that convey a plan, program, or project in a concise and visual template [22]. Rational models increase the likelihood of a program succeeding because they determine potential barriers to program implementation, goals, target audiences, required actions for optimal outcomes, and expected outcomes [23]. Therefore, this meta-analysis was conducted to determine the best interventions and then develop a conceptual framework of a logical model, based on the characteristics of effective interventions regarding hand hygiene adherence.

\section{Materials and Methods}

This review was conducted based on the PRISMA checklist (Preferred Reporting Items for Systematic Reviews and Meta-Analysis).

The research questions were as follows:

(i) What are the most effective interventions for improving hand hygiene compliance?

(ii) How can a logic model be drawn based on the characteristics of effective interventions?

2.1. Search Strategy. In order to find interventional studies on improving hand hygiene adherence, PubMed, ProQuest, Web of Knowledge, Scopus, Cochrane Library, and ScienceDirect databases were searched up to December 21, 2019, without a time limit. Additionally, a list of references of similar studies and relevant systematic reviews was examined for further information. The search strategy was developed by the experienced research team (Appendix).

The keywords used in the initial search were (Compliance OR adherence) AND (Nurses OR healthcare worker OR healthcare practitioner OR infection control worker OR infection control practitioner OR infection control staff OR infection control personnel OR healthcare provider) AND (hand hygiene OR hand wash*).

The collected data were entered in EndNote X7 software and duplicate articles were removed automatically. It is worth noting that two researchers examined the articles separately.

2.2. Eligibility Criteria. All studies with the following criteria were included: (a) randomized controlled trials (RCT), in which at least one intervention had been performed to improve healthcare provider compliance to hand hygiene; (b) studies that determined the level of hand hygiene compliance; and (c) studies conducted on health practitioners working at hospitals. The exclusion criteria were as follows: (a) abstracts without full text, (b) abstracts and congress and conference reports in nonarticle structure, (c) studies that were not original articles, and (d) non-English language studies.

2.3. Extracting Data. An initial search for studies was conducted by two authors of this study (M. MJ and S. H). Screening, extracting the results, and assessing the quality were carried out by these two individuals separately. In case of inconsistency between the two judgments, the supervisor determined the final comment on that article ( $\mathrm{MH}$. K).

2.4. Risk of Bias among Studies. A random-effects model was used to reduce the risk of bias in studies. The Egger test and funnel plot were used to examine publication bias.

2.5. Statistical Analysis. Heterogeneity among studies was measured using Cochran's test (with significance level $<0.1$ ) and their combination was examined using $I^{2}$ statistics. In the case of heterogeneity, a random-effects model with the inverse-variance method was applied. All analyses were performed using Comprehensive Meta-Analysis (CMA) software version 2 .

2.6. Effect Size. The effect size used in this study was the calculated odds ratio (OR) index. Odds ratio indicator allows the different results to be combined and presented in a comprehensible way. CMA software has the ability to combine different indices, as well as combining the effect of the sample size and the difference of the index being compared. Thus, the reasons for using the odds ratio were the different indicators, measurement scales, and data analysis methods based on the subgroups in the studies.

The calculated OR eliminates all these restrictions and provides a more meaningful indicator. The calculated OR can be interpreted in the following way: if the OR is greater than one, the intervention is beneficial. If the OR is equal to 1 , the odds of one event are the same for both groups, while if the OR is less than one, the intervention has a reverse effect. 
2.7. Development of a Logic Model. Finally, a logic model was created and developed based on the characteristics of effective interventions to provide a conceptual framework for the improvement of hand hygiene adherence. A logic model clarifies the logic of a program in terms of achieving its goals and objectives [24]. The components of a logic model consist of inputs, processes, and outcomes [25]. Inputs are the resources that will later be transformed into outcomes and should be specified as part of planned activities [26]. The process demonstrates how the theories, methods, and activities of the planned program act in service of the goal with regard to the participants [27]. Outcomes illustrate what the program achieves in terms of knowledge, attitudes, and skills among participants [28].

\section{Results}

3.1. Quality Assessment. The checklist for a randomized controlled trial prepared by the Joanna Briggs Institute (JBI) [29] was used for quality assessment. The studies were assessed using the checklist items. Figure 1 shows the quality of the articles.

3.1.1. Search Description. After searching all international databases, 2363 articles were initially found. After removing duplicate articles, 1920 articles were examined in terms of topic and abstract, out of which 141 articles entered the next stage. At this stage, the full texts of the articles were examined, and 14 RCT articles entered the final analysis. It should be noted that the references of the articles included were also reviewed to add relevant studies. In the screening stage, some studies were excluded for several reasons, due to irrelevant topics and irrelevant study populations. The flowchart of the included studies is presented in Figure 2.

3.1.2. Characteristics of the Studies Included. 14 randomized clinical trials were found by the researchers, of which 4 studies were conducted in the Netherlands, while the rest were conducted in China, Germany, Indonesia, Sweden, Finland, Hong Kong, Spain, England, Canada, and the United States [30-43]. Of these, 12 studies were included in the meta-analysis, since they had identified the percentage of hand hygiene compliance. The characteristics of the randomized clinical trials included in the meta-analysis are presented in Table 1.

\subsection{Meta-Analysis and Data Synthesis}

3.2.1. Heterogeneity. The result of the chi-squared test and the $I^{2}$ index indicated that there was considerable betweenstudy heterogeneity. Due to the high heterogeneity in results, the random effect model was used to estimate the overall odds ratio.

3.3. Synthesis of Results. In this study, the overall odds ratio was 1.74 with a 95\% confidence interval (1.62-1.86), $P<0.001$. The results of the meta-analyses are displayed in Figure 3.
The results showed that the multimodel strategy (alcohol-based hand rub + video + reminders + feedback + health talk + powerless gloves) conducted by Ho et al. [33], with a higher odds ratio and smaller variation span, was the most effective intervention in terms of hand hygiene adherence $\left(\mathrm{OR}=18.4, \quad 95 \%\right.$ CI $(13.6-24.8), \quad P<0.001, I^{2}=95.8 \%$, $P<0.001)$.

In a study conducted by Martín-Madrazo et al. [38], the intervention group which involved training sessions, the application of hydroalcoholic solutions, and setting reminder posters showed greater effectiveness than the control group (OR=8.78, 95\% CI (2.7-27.7), $P<0.001, I^{2}=99.1 \%$, $P<0.001)$.

In Huis et al.'s study in 2011 [35], an extended strategy targeting social impact and sustained leadership in the intervention group showed more effectiveness, compared with a control group $(\mathrm{OR}=3.35,95 \%$ CI (2.04-5.51), $P<0.001$, $\left.I^{2}=95.8 \%, P<0.001\right)$.

In another study performed by Stewardson et al. [41], the intervention group that used sustained performance feedback and patient participation showed more effectiveness compared to a control group $(\mathrm{OR}=1.47,95 \% \mathrm{CI}(1.07-2.03)$, $\left.P=0.01, I^{2}=95.2 \%, P<0.001\right)$.

The research conducted by Mertz et al. [39] revealed that the intervention group with performance feedback and small group educational seminars showed more effectiveness than the control group $(\mathrm{OR}=1.31,95 \% \mathrm{CI}(1.08-1.59), P=0.005$, $\left.I^{2}=88.0 \%, P<0.001\right)$.

Xiong et al. [43] indicated that multimedia training sessions, video presentation, role-playing, and feedback in the intervention group were more effective in comparison with self-learning in the control group $(\mathrm{OR}=10.75,95 \% \mathrm{CI}$ (3.8-30.3), $\left.P<0.001, I^{2}=99.3 \%, P<0.001\right)$.

Huis et al. conducted two studies in 2013 [34, 36]. A team and leaders-directed (TDS) strategy were used in the intervention group of both studies and eventually, the intervention group showed a significantly improved effectiveness, compared with the control group $(\mathrm{OR}=1.6,95 \% \mathrm{CI}$ (1.46-1.93), $\left.P<0.001, I^{2}=85.9 \%, P<0.001\right)$.

Finally, the results of the intervention groups in four studies included an intervention using active presentation and role modeling [40], a tailored intervention based on health action process approach (HAPA) [42], an intervention that included simulated sessions [37], and a feedback intervention using goal setting and control and operantlearning theories [32] did not show a statistically significant difference compared with the control groups.

3.3.1. Assessing Publication Bias. Based on the results of Egger's test, publication bias was observed among the studies $(P<0.001)$. Figure 4 shows the funnel plot of the studies.

\section{Discussion}

The main aim of the present meta-analysis was to determine the most effective intervention, as well as its most influential components, in improving hand hygiene. In analyses stratified by type of intervention among 9 RCTs with 


\begin{tabular}{|c|c|c|c|c|c|c|c|c|c|c|c|c|c|}
\hline & 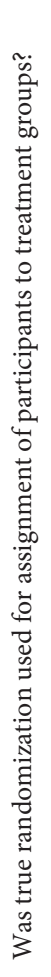 & 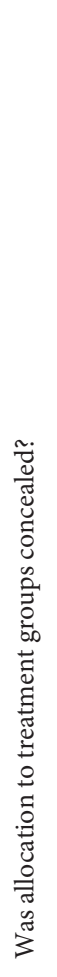 & 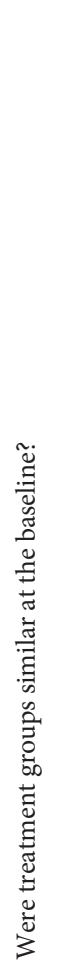 & 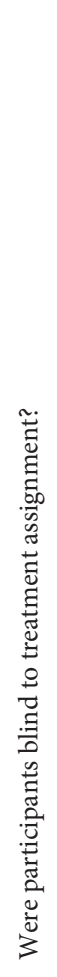 & 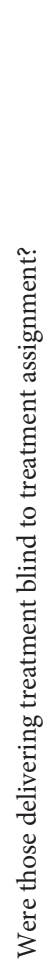 & 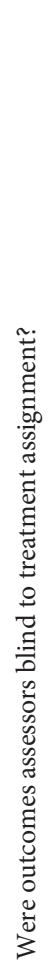 & 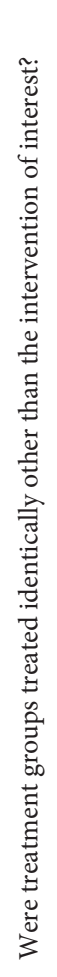 & 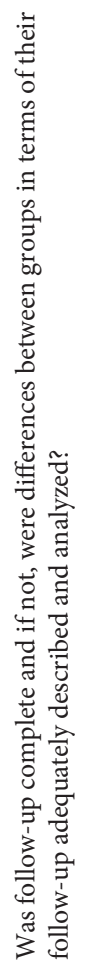 & 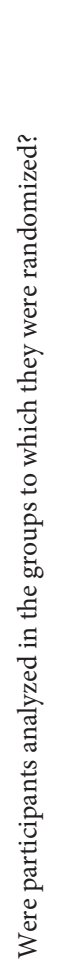 & 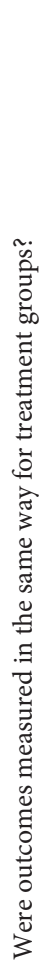 & 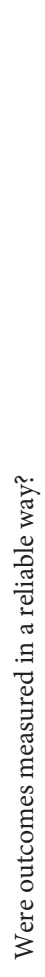 & 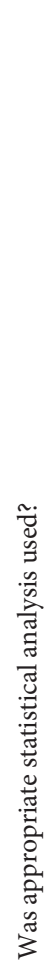 & 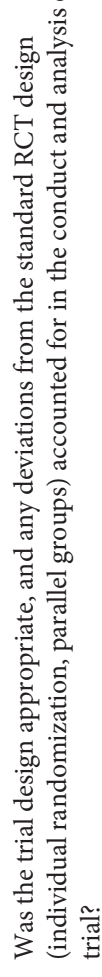 \\
\hline 1-Xiong, 2017 & $\checkmark$ & $\checkmark$ & o & 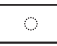 & ᄋ & @ & $\checkmark$ & $\checkmark$ & $\checkmark$ & $\bullet$ & $\checkmark$ & $\checkmark$ & $\checkmark$ \\
\hline 2-Santosaningsih, 2017 & $\checkmark$ & $\checkmark$ & e & 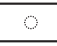 & e & e & $\checkmark$ & $\checkmark$ & $\checkmark$ & $\bullet$ & $\checkmark$ & $\checkmark$ & $\checkmark$ \\
\hline 3-Von Lengerke, 2017 & $\checkmark$ & $\checkmark$ & a & $\checkmark$ & $x$ & $x$ & $\checkmark$ & $\checkmark$ & $\checkmark$ & $\bullet$ & $\checkmark$ & $\checkmark$ & $\checkmark$ \\
\hline 4-Jansson, 2016 & $\checkmark$ & $\checkmark$ & $\checkmark$ & $x$ & $\checkmark$ & $\checkmark$ & $\checkmark$ & $\checkmark$ & $\checkmark$ & $\bullet$ & $\checkmark$ & $\checkmark$ & $\checkmark$ \\
\hline 5-Stewardson, 2016 & $\checkmark$ & $\checkmark$ & a & $x$ & म & $x$ & $\checkmark$ & $\checkmark$ & $\checkmark$ & $\checkmark$ & $\checkmark$ & $\checkmark$ & $\checkmark$ \\
\hline 6-Fisher, 2013 & $\checkmark$ & $\checkmark$ & $\checkmark$ & 8 & e & @ & $\checkmark$ & e & $\checkmark$ & $\bullet$ & $\checkmark$ & $\checkmark$ & $\checkmark$ \\
\hline 7-Huis and schoon, 2013 & $\checkmark$ & $\checkmark$ & $\checkmark$ & $\checkmark$ & $\checkmark$ & $\checkmark$ & $\checkmark$ & $\checkmark$ & $\checkmark$ & $\bullet$ & $\checkmark$ & $\checkmark$ & $\checkmark$ \\
\hline 8-Huis and Hulscher, 2013 & $\checkmark$ & ह & @ & $\checkmark$ & ᄋ & \% & $\checkmark$ & $\checkmark$ & $\checkmark$ & $\checkmark$ & $\checkmark$ & $\checkmark$ & $\checkmark$ \\
\hline 9-Fuller, 2012 & $\checkmark$ & $\checkmark$ & 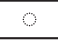 & s & e & $\checkmark$ & $\checkmark$ & $\checkmark$ & $\checkmark$ & $\checkmark$ & $\checkmark$ & $\checkmark$ & 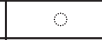 \\
\hline 10-Martı'nMadrazo, 2012 & $\checkmark$ & $\checkmark$ & e & e & e & @ & $\checkmark$ & $\checkmark$ & $\checkmark$ & $\checkmark$ & $\checkmark$ & $\checkmark$ & $\checkmark$ \\
\hline 11-Mei-lin Ho, 2012 & $\checkmark$ & $\checkmark$ & a & $\checkmark$ & $x$ & $x$ & $\checkmark$ & $\checkmark$ & $\checkmark$ & $\checkmark$ & $\checkmark$ & $\checkmark$ & $\checkmark$ \\
\hline 12-Erasmus, 2011 & $\checkmark$ & $\checkmark$ & e & o & 8 & $\checkmark$ & $\checkmark$ & $\checkmark$ & $\checkmark$ & $\bullet$ & $\checkmark$ & $\checkmark$ & $\checkmark$ \\
\hline 13-Huis, 2011 & $\checkmark$ & $\checkmark$ & e & e & @ & $\checkmark$ & $\checkmark$ & $\checkmark$ & $\checkmark$ & $\checkmark$ & $\checkmark$ & $\checkmark$ & i \\
\hline 14-Mertz, 2010 & $\checkmark$ & $\checkmark$ & $\checkmark$ & $\checkmark$ & @ & $\checkmark$ & $\checkmark$ & $\checkmark$ & $\checkmark$ & $\bullet$ & $\checkmark$ & $\checkmark$ & $\checkmark$ \\
\hline
\end{tabular}

FIGURE 1: Assessment risk of bias in included studies of randomized clinical trial studies to promote hand hygiene of healthcare workers.

effective strategies, a multimodel strategy in the study of Ho et al. was recognized as the most effective intervention, affecting three levels: individual, interpersonal, and organizational. In this intervention, provision of facilities, health talk, train-the-trainer approach, feedback, reminders, and performance reports were seen to work effectively [33]. Schölmerich and Kawachi, in line with this finding, stated that multilevel interventions inspired by socioecological models enhance the impact of programs by simultaneously altering the individual, social, and organizational levels [44].

According to the findings, another effective strategy, which had an impact on both individual and organizational levels, involved providing facilities, training, and reminder posters [38]. Naikoba and Hayward confirmed that strategies including supplemental interventions such as education, reminders, and giving feedback are more useful than strategies that only provided more facilities [45].

Several successful studies using a team and leaders-directed strategy affected two levels: interpersonal (social influence) and organizational (sustained leadership and managers) [34, 36]. The evidence suggests that team-based strategies can be effective in improving hand hygiene adherence $[36,46]$. Huis et al. stated that team-based strategies emphasize social influence, team effectiveness, and leadership theory as well as providing a way to develop hand hygiene behavior at the interpersonal and organizational levels [36].

Based on the results, performance feedback (organizational level) in conjunction with feedback involving patient participation (interpersonal level) was another successful strategy [39]. Jansson et al. similarly presented 


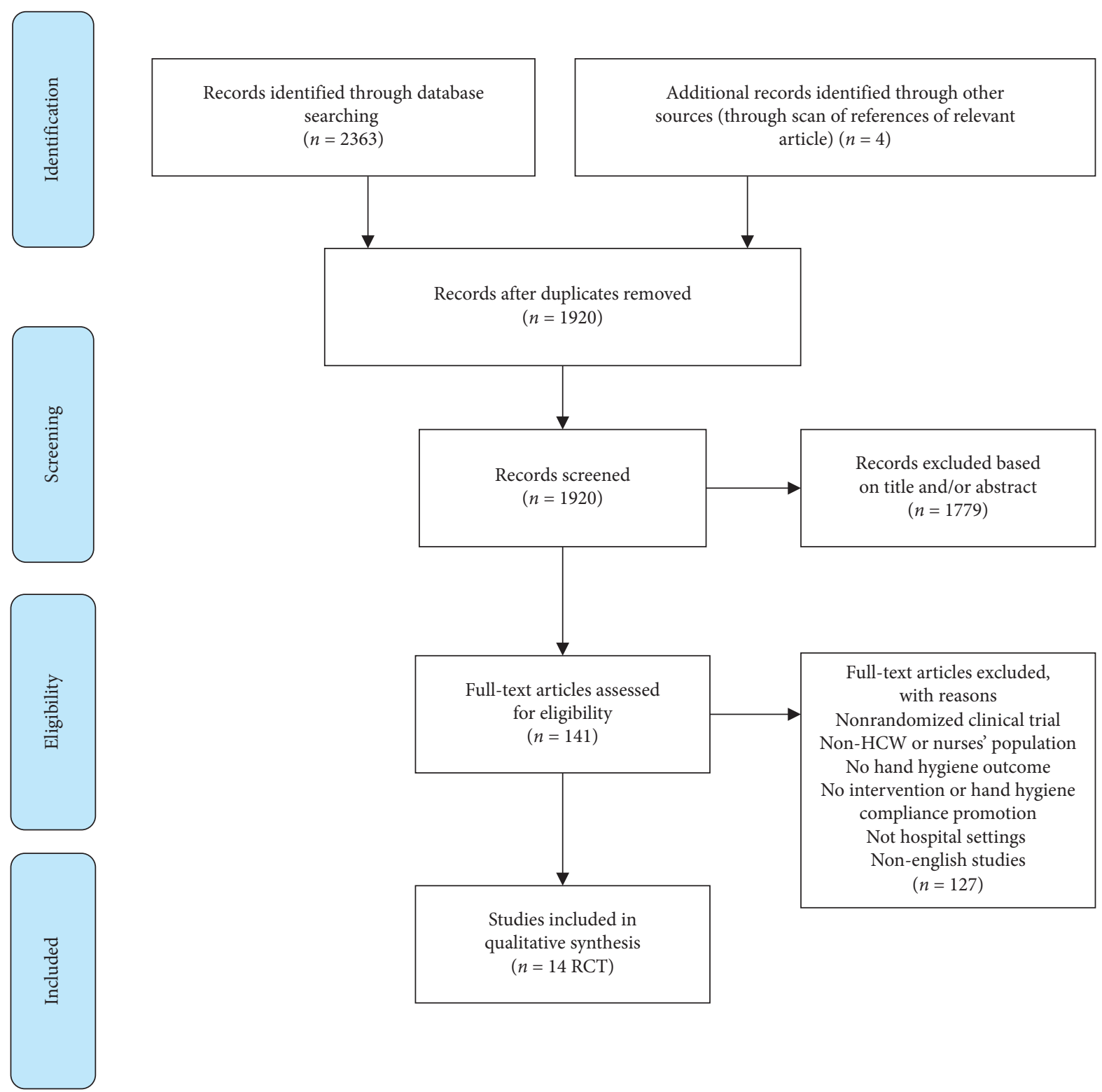

FIGURE 2: Search process and study identification systematic review of randomized clinical trial studies to promote hand hygiene in healthcare workers.

a successful strategy of sustained feedback and small group training seminars at organizational and interpersonal levels [37]. Several studies in line with this finding explained that patient requests for hand hygiene compliance, along with continuous performance feedback (immediate verbal feedback, giving hand hygiene observation cards, and personalized advice by supervisors and managers) can have a significant impact on hand hygiene adherence [41, 47, 48].

Another strategy involving mixed-media education and feedback had a significant impact on promoting hand hygiene adherence at both interpersonal and organizational levels [41]. It seems that using mixed-media education can improve the individuals' capacity to use learned theoretical concepts to solve real-world problems [49]. Consistent with this finding, Chun et al. believed that various methods of education about hand hygiene, linked with subsequent feedback, would improve the frequency and quality of hand hygiene activities and will also increase awareness [50].

\subsection{A Proposed Logic Model for Designing Interventions.} According to the results, there is a missing point in designing the successful strategies; they did not pay attention to situational analysis and therefore the interventions were not systematically designed. Situation analysis is important because it refers to information gathering and analysis of the context's current state in terms of physical conditions, material, human resources, and so forth, which can have a significant impact on the selection of appropriate and accurate strategies [51]. Since logic models are designed based 


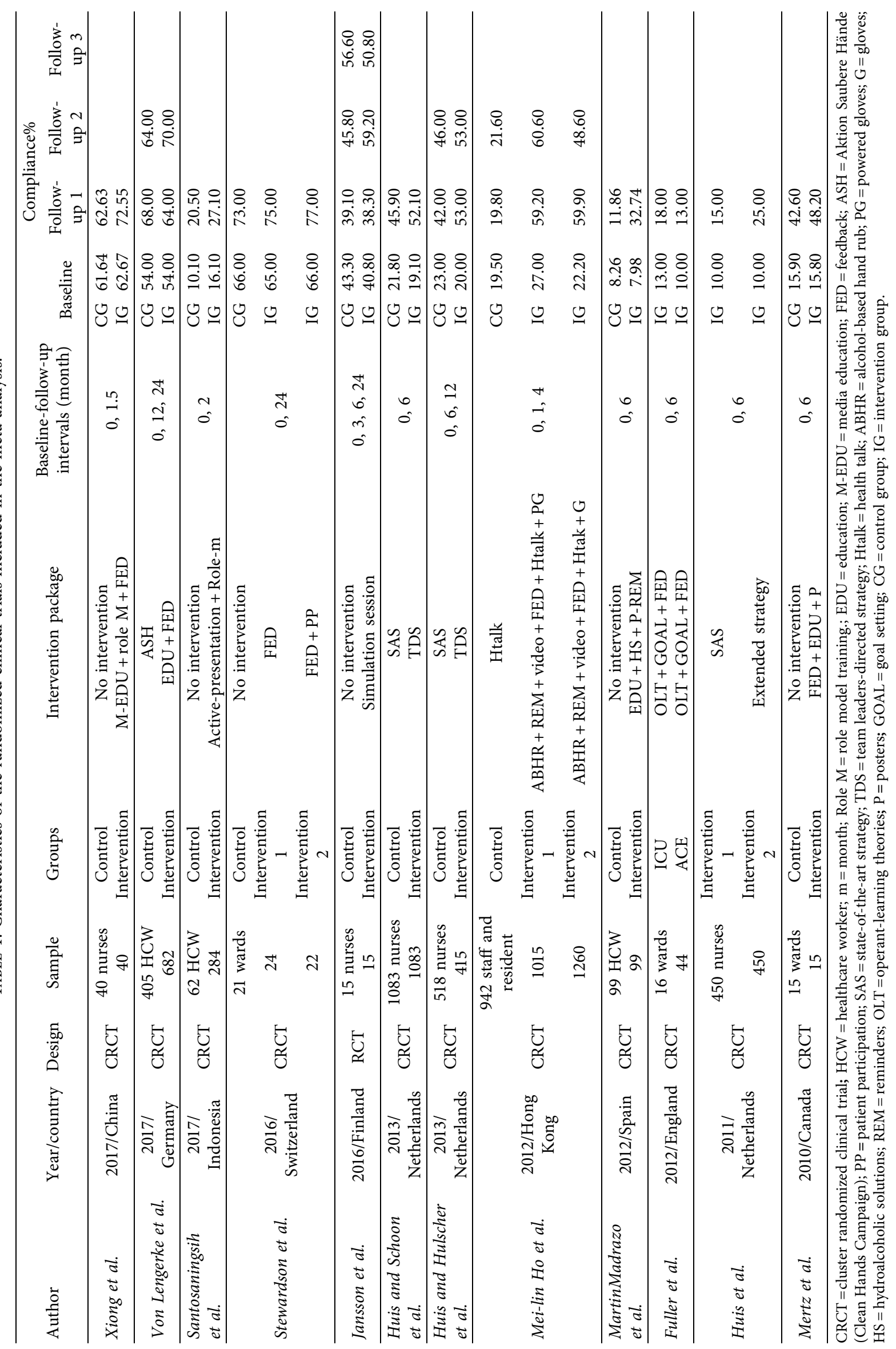




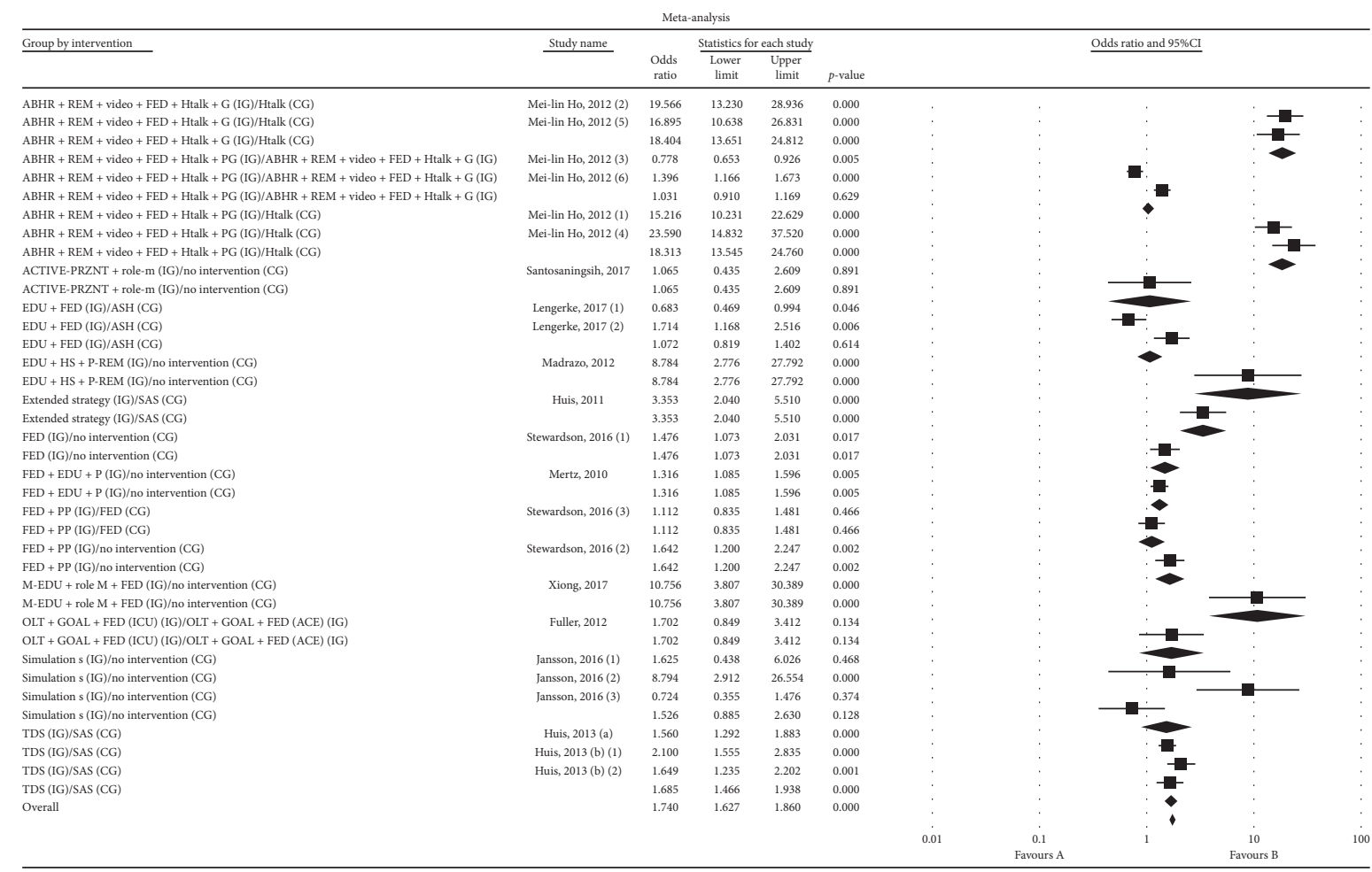

FIGURE 3: Forest plot accumulation curve: the effect of interventions compared to other groups (95\% confidence interval).

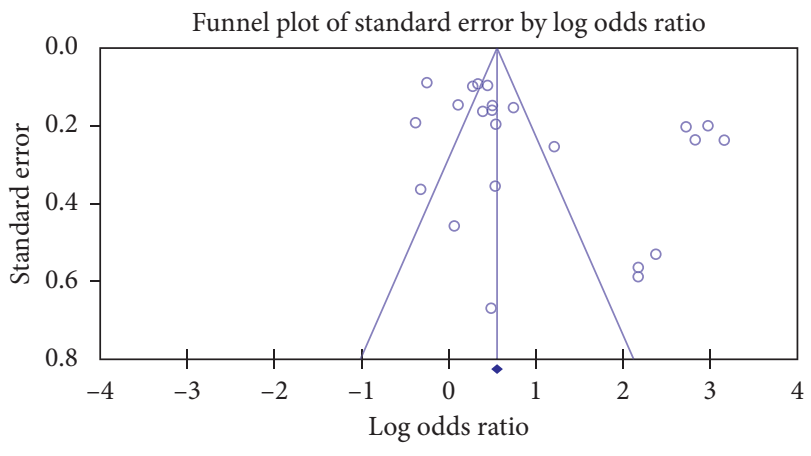

FIgURE 4: Funnel plot of included studies.

on situational analysis, the authors of this paper decided to propose a logic model for improving hand hygiene compliance. In fact, a logic model is a simplified visual representation of the typology of interventions; processes; and short-term, mediumterm, and long-term outcomes that can be a suitable platform for a realistic systematic review [52-54].

The proposed logic model was designed based on a socioecological approach (individual, interpersonal, and organizational levels). In the first step, a situational analysis of the current state of the context in terms of hand hygiene behavior in employees, group norms, physical environment characteristics, nosocomial infection rate, and organizational dynamics (resources, organizational policies, and leadership style) is performed (Table 2).

In the input part of Table 2, it is specified that, to improve hand hygiene, interventions should be tailored for the target groups in the clinical environment, including healthcare workers, patients, supervisors, and decision-makers. The change objectives should be also determined in relation to the target groups.

In the process section, at the individual level, it is important to use different activities to improve knowledge, perceptions, and attitudes towards hand hygiene compliance. The best theories for planning activities at this level involve using empowerment-oriented behavior change theories, such as Theory of Planned Behavior (TPB) [55] and Freire's model of adult education [56].

At the interpersonal level, activities may be planned according to social norms theory $[57,58]$, while organizational change theory [59] may be used at the organizational level. In the activities section, several activities based on theory and methods are suggested for planners. Short-term outcomes show the effect of interventions on attitudes, perceptions, knowledge, and beliefs; changes in behavior, decision-making, and action are considered as mediumterm outcomes; long-term outcomes involve major changes in status [60]. These outcomes are suggested based on the hand hygiene topic in the logic model.

\section{Limitations}

One of the most important limitations of this study was the existence of different reports on the effectiveness of each intervention, which made it difficult to combine the studies. However, combining the results was made possible by using the capabilities of CMA software. A second limitation was reviewing only studies that measured hand hygiene adherence as a percentage via behavioral observation so that the studies 
TABle 2: A logic model based on a socioecological approach delineating inputs, processes, and outcomes to improve hand hygiene compliance.

\begin{tabular}{|c|c|c|c|c|c|c|c|c|c|}
\hline Context & \multicolumn{2}{|c|}{ Input } & \multicolumn{4}{|c|}{ Process } & \multicolumn{3}{|c|}{ Outcome } \\
\hline $\begin{array}{l}\text { Situational } \\
\text { analysis }\end{array}$ & $\begin{array}{c}\text { Intervention } \\
\text { target }\end{array}$ & $\begin{array}{c}\text { Target } \\
\text { audience }\end{array}$ & $\begin{array}{l}\text { Change } \\
\text { objectives }\end{array}$ & Theory & Methods & Activities & $\begin{array}{l}\text { Short-term } \\
\text { outcomes }\end{array}$ & $\begin{array}{l}\text { Medium-term } \\
\text { outcomes }\end{array}$ & $\begin{array}{l}\text { Long-term } \\
\text { outcomes }\end{array}$ \\
\hline & $\begin{array}{l}\text { Influence } \\
\text { individuals }\end{array}$ & $\begin{array}{c}\text { Healthcare } \\
\text { workers } \\
\text { (HCWs), } \\
\text { patients }\end{array}$ & $\begin{array}{l}\text { Hand hygiene } \\
\text { compliance }\end{array}$ & $\begin{array}{l}\text { (i) Theory of } \\
\text { Planned } \\
\text { Behavior (TPB) } \\
\text { (ii) Freire's } \\
\text { model of adult } \\
\text { education }\end{array}$ & $\begin{array}{l}\text { (i) } \\
\text { Discussion } \\
\text { (ii) } \\
\text { Problem- } \\
\text { based } \\
\text { learning } \\
\text { (iii) Guided } \\
\text { exploration }\end{array}$ & $\begin{array}{l}\text { (i) Identifying the } \\
\text { advantages and } \\
\text { disadvantages of } \\
\text { performing hand } \\
\text { hygiene } \\
\text { (ii) Determining } \\
\text { people whose } \\
\text { approval is } \\
\text { important for the } \\
\text { person to do hand } \\
\text { hygiene } \\
\text { (iii) Identifying } \\
\text { barriers to } \\
\text { performing hand } \\
\text { hygiene } \\
\text { (iv) Identifying } \\
\text { facilitators to } \\
\text { performing hand } \\
\text { hygiene } \\
\text { (v) Brainstorming } \\
\text { root causes of poor } \\
\text { hand hygiene } \\
\text { adherence } \\
\text { (vi) Personalizing } \\
\text { the issue and using } \\
\text { role-plays to } \\
\text { generate emotions }\end{array}$ & $\begin{array}{l}\text { (i) Improved } \\
\text { knowledge, } \\
\text { perception, } \\
\text { and attitudes } \\
\text { about hand } \\
\text { hygiene } \\
\text { compliance }\end{array}$ & $\begin{array}{l}\text { (i) Compliance } \\
\text { with the WHO } \\
\text { " } 5 \text { moments of } \\
\text { hand hygiene" } \\
\text { responsibly } \\
\text { (ii) Sustained } \\
\text { improvement in } \\
\text { hand hygiene }\end{array}$ & \\
\hline & $\begin{array}{c}\text { Influence } \\
\text { interpersonal } \\
\text { level }\end{array}$ & $\begin{array}{c}\text { Coworkers } \\
\text { and } \\
\text { supervisors }\end{array}$ & $\begin{array}{l}\text { Supportive } \\
\text { behavior } \\
\text { Emotional, } \\
\text { informational, } \\
\text { appraisal, and } \\
\text { instrumental } \\
\text { support }\end{array}$ & $\begin{array}{l}\text { (i) Social norms } \\
\text { theory }\end{array}$ & $\begin{array}{l}\text { (i) The } \\
\text { train-the- } \\
\text { trainer } \\
\text { method }\end{array}$ & $\begin{array}{l}\text { (i) Participatory } \\
\text { discussions between } \\
\text { HCWs about hand } \\
\text { hygiene compliance } \\
\text { (ii) Creation of new } \\
\text { knowledge in a } \\
\text { selected group of } \\
\text { participants } \\
\text { (iii) Sharing } \\
\text { knowledge with } \\
\text { others }\end{array}$ & $\begin{array}{l}\text { (i) Improved } \\
\text { social norms } \\
\text { about hand } \\
\text { hygiene in } \\
\text { workplace }\end{array}$ & $\begin{array}{l}\text { (i) Social } \\
\text { approval for } \\
\text { hand hygiene } \\
\text { compliance } \\
\text { (ii) HCWs } \\
\text { imitate each } \\
\text { other in } \\
\text { performing hand } \\
\text { hygiene } \\
\text { (iii) Sustained } \\
\text { improvement in } \\
\text { hand hygiene }\end{array}$ & $\begin{array}{l}\text { (i) Reduced } \\
\text { nosocomial } \\
\text { infections }\end{array}$ \\
\hline & $\begin{array}{c}\text { Influence } \\
\text { organizational } \\
\text { level }\end{array}$ & $\begin{array}{c}\text { Decision- } \\
\text { makers }\end{array}$ & $\begin{array}{l}\text { Supportive } \\
\text { environment: } \\
\text { policies and } \\
\text { regulations }\end{array}$ & $\begin{array}{l}\text { Organizational } \\
\text { change theory }\end{array}$ & $\begin{array}{l}\text { (i) Planning } \\
\text { (ii) } \\
\text { Monitoring } \\
\text { (iii) } \\
\text { Reviewing } \\
\text { (iv) } \\
\text { Rewarding }\end{array}$ & $\begin{array}{l}\text { (i) Designing new } \\
\text { and innovative } \\
\text { policy for improving } \\
\text { hand hygiene } \\
\text { (ii) Providing the } \\
\text { essential materials } \\
\text { and equipment for } \\
\text { hand hygiene } \\
\text { compliance } \\
\text { (iii) Continuous } \\
\text { monitoring of hand } \\
\text { hygiene compliance } \\
\text { among staff and } \\
\text { patients } \\
\text { (iv) Appropriate } \\
\text { reaction to hand } \\
\text { hygiene behavior at } \\
\text { the right time and } \\
\text { place } \\
\text { (v) Performance } \\
\text { review with } \\
\text { employee self- } \\
\text { assessment } \\
\text { (vi) Encouragement } \\
\text { of wards that have } \\
\text { the highest hand } \\
\text { hygiene and the } \\
\text { lowest nosocomial } \\
\text { infections }\end{array}$ & $\begin{array}{l}\text { (i) Responsive } \\
\text { policy for } \\
\text { improving } \\
\text { hand hygiene }\end{array}$ & $\begin{array}{l}\text { (i) Sustained } \\
\text { leadership } \\
\text { (ii) Continuous } \\
\text { evaluation } \\
\text { (iii) Sufficient } \\
\text { facilities } \\
\text { (iv) Sustained } \\
\text { improvement in } \\
\text { hand hygiene }\end{array}$ & \\
\hline
\end{tabular}


were excluded involving self-reporting and assessing the quality of the process. The last limitation was that almost all studies were conducted at well-equipped hospitals in developed countries, so generalization of the results to other hospitals or less developed countries should be made with caution.

\section{Conclusions}

The present meta-analysis identifies that the use of a socioecological approach in planning comprehensive and coordinated interventions (which target behavioral determinants at multiple levels of influence) is significantly more effective than other multiple-level strategies. Therefore, the authors of this study present a new theory-based logic model that can be an appropriate guide for planning, implementing, and evaluating an intervention at these three levels. It is suggested that decision-makers, planners, and managers in hospitals use this proposed logic model for setting up interventions to improve hand hygiene so that they can design a comprehensive and effective intervention. Future studies can be performed to determine the effectiveness of the proposed logic model in the field and different healthcare scenarios.

\section{Data Availability}

This manuscript is a systematic review and meta-analysis. Different tables used to support the findings of this study are included in the article. The search strategy process used to support the findings of this study is included within the supplementary information file. Requests for access to the endnote file should be sent to Mohadeseh Motamed-Jahromi, e-mail: mohadesehmotamed@yahoo.com.

\section{Conflicts of Interest}

The authors declare that they have no conflicts of interest.

\section{Authors' Contributions}

MHK conceived and supervised the study; MHK and MM-J contributed equally to interpreting the findings and writing the manuscript; $\mathrm{SH}$ analyzed data and helped to write methods and results. All the authors reviewed the results and approved the final version of the manuscript.

\section{Acknowledgments}

This study was partially supported by the research deputy of Shiraz University of Medical Science.

\section{Supplementary Materials}

Appendix Aa: search strategies in PubMed, ProQuest, Web of Knowledge, Scopus, Cochrane Library, and ScienceDirect database. (Supplementary Materials)

\section{References}

[1] B. Allegranzi, A. Gayet-Ageron, N. Damani et al., "Global implementation of WHO's multimodal strategy for improvement of hand hygiene: a quasi-experimental study," The Lancet Infectious Diseases, vol. 13, no. 10, pp. 843-851, 2013.

[2] D. O. Duerink, D. Roeshadi, H. Wahjono et al., "Surveillance of healthcare-associated infections in Indonesian hospitals," Journal of Hospital Infection, vol. 62, no. 2, pp. 219-229, 2006.

[3] E. S. Gurley, R. U. Zaman, R. Sultana et al., "Rates of hospitalacquired respiratory illness in Bangladeshi tertiary care hospitals: results from a low-cost pilot surveillance strategy," Clinical Infectious Diseases, vol. 50, no. 8, pp. 1084-1090, 2010.

[4] A. Huis, T. van Achterberg, M. de Bruin, R. Grol, L. Schoonhoven, and M. Hulscher, "A systematic review of hand hygiene improvement strategies: a behavioural approach," Implementation Science, vol. 7, no. 1, p. 92, 2012.

[5] I. K. Murni, T. Duke, S. Kinney, A. J. Daley, and Y. Soenarto, "Reducing hospital-acquired infections and improving the rational use of antibiotics in a developing country: an effectiveness study," Archives of Disease in Childhood, vol. 100, 2014.

[6] WHO, Prevention of Hospital-Acquired Infections: A Practical Guide, World Health Organization, Geneva, Switzerland, 2002.

[7] B. Philips, Best Practices in Infection Prevention and Control: An International Perspective, Oxford University Press, Oxford, UK, 2012.

[8] H. J. Lane, N. Blum, E. Fee, and O. W. Holmes, “(1809-1894) and Ignaz Philipp Semmelweis (1818-1865): preventing the transmission of puerperal fever," American Journal of Public Health, vol. 100, no. 6, pp. 1008-1009, 2010.

[9] E. A. Mortimer, P. J. Lipsitz, E. Wolinsky, A. J. Gonzaga, and C. H. Rammelkamp, "Transmission of staphylococci between newborns," American Journal of Diseases of Children, vol. 104, no. 3, pp. 289-295, 1962.

[10] J. Khan, I. Ahmad, N. Basharat et al., Prevalence, Risk Factors and Antibiogram Analysis of Nosocomial Infection in Tertiary Care Hospital of Rawalpindi, Pakistan, 2021.

[11] A. R. Marra, D. F. Moura, A. T. Paes, O. F. P. Dos Santos, and M. B. Edmond, "Measuring rates of hand hygiene adherence in the intensive care setting: a comparative study of direct observation, product usage, and electronic counting devices," Infection Control \& Hospital Epidemiology, vol. 31, no. 8, pp. 796-801, 2010.

[12] H. Sax, B. Allegranzi, M.-N. Chraiti, J. Boyce, E. Larson, and D. Pittet, "The World Health Organization hand hygiene observation method," American Journal of Infection Control, vol. 37, no. 10, pp. 827-834, 2009.

[13] A. D. Harris, M. H. Samore, R. Nafziger, K. DiRosario, M. C. Roghmann, and Y. Carmeli, "A survey on handwashing practices and opinions of healthcare workers," Journal of Hospital Infection, vol. 45, no. 4, pp. 318-321, 2000.

[14] M. G. Lankford, T. R. Zembower, W. E. Trick, D. M. Hacek, G. A. Noskin, and L. R. Peterson, "Influence of role models and hospital design on the hand hygiene of health-care workers," Emerging Infectious Diseases, vol. 9, no. 2, pp. 217-223, 2003.

[15] WHO, WHO Guidelines on Hand Hygiene in Health Care, WHO, Geneva, Switzerland, 2009.

[16] A. Jamal, G. O’Grady, E. Harnett, D. Dalton, and D. Andresen, "Improving hand hygiene in a paediatric hospital: a multimodal quality improvement approach," $B M J$ Quality \& Safety, vol. 21, no. 2, pp. 171-176, 2012.

[17] B. Allegranzi, H. Sax, L. Bengaly et al., "Successful implementation of the World Health Organization hand hygiene improvement strategy in a referral hospital in Mali, Africa," 
Infection Control \& Hospital Epidemiology, vol. 31, no. 2, pp. 133-141, 2010.

[18] A. A. Alshehari, S. Park, and H. Rashid, "Strategies to improve hand hygiene compliance among health care workers in adult intensive care units: a mini systematic review," Journal of Hospital Infection, vol. 100, no. 2, pp. 152-158, 2018.

[19] S. Lydon, M. Power, J. McSharry et al., "Interventions to improve hand hygiene compliance in the ICU," Critical Care Medicine, vol. 45, no. 11, pp. e1165-e1172, 2017.

[20] N. Luangasanatip, M. Hongsuwan, D. Limmathurotsakul et al., "Comparative efficacy of interventions to promote hand hygiene in hospital: systematic review and network metaanalysis," BMJ, vol. 351, Article ID h3728, 2015.

[21] R. Pawson, T. Greenhalgh, G. Harvey, and K. Walshe, "Realist review-a new method of systematic review designed for complex policy interventions," Journal of Health Services Research \& Policy, vol. 10, no. 1_suppl, pp. 21-34, 2005.

[22] L. W. Knowlton and C. C. Phillips, The Logic Model Guidebook: Better Strategies for Great Results, Sage, Newcastle upon Tyne, UK, 2012.

[23] T. Henriques and H. O’Neill, Action, Design and Research-A Logical Data Model. Action, Design and Research-A Logical Data Model, 2020.

[24] R. Guo, B. A. Bain, and J. Willer, "Application of a logic model to an evidence-based practice training program for speechlanguage pathologists and audiologists," Journal of Allied Health, vol. 40, no. 1, pp. 23E-28E, 2011.

[25] M. Huhman, C. Heitzler, and F. Wong, "The VERB ${ }^{\mathrm{TM}}$ campaign logic model: a tool for planning and evaluation," Preventing Chronic Disease, vol. 1, no. 3, 2004.

[26] B. M. Das and M. L. Sartore-Baldwin, "Development of a logic model for a service learning, dog walking course for college students," Evaluation and Program Planning, vol. 76, Article ID 101667, 2019.

[27] B. Turnock, Essentials of Public Health, Jones \& Bartlett Publishers, Burlington, MA, USA, 2011.

[28] C. Keane, Modeling Behavior in Complex Public Health Systems: Simulation and Games for Action and Evaluation, Springer Publishing Company, Berlin, Germany, 2013.

[29] Joanna Briggs Institute TJaCfrctA, https://joannabriggs.org/ assets/docs/critical-appraisaltools/TUoARf,\%20JBI_RCTs_ Appraisal_tool2017.pdf.

[30] V. Erasmus, A. Huis, A. Oenema et al., "The ACCOMPLISH study. A cluster randomised trial on the cost-effectiveness of a multicomponent intervention to improve hand hygiene compliance and reduce healthcare associated infections," BMC Public Health, vol. 11, no. 1, p. 721, 2011.

[31] D. A. Fisher, T. Seetoh, H. O. May-Lin et al., "Automated measures of hand hygiene compliance among healthcare workers using ultrasound: validation and a randomized controlled trial," Infection Control \& Hospital Epidemiology, vol. 34, no. 9, pp. 919-928, 2013.

[32] C. Fuller, S. Michie, J. Savage et al., “The feedback intervention trial (FIT)-improving hand-hygiene compliance in UK healthcare workers: a stepped wedge cluster randomised controlled trial," PLoS One, vol. 7, no. 10, Article ID e41617, 2012.

[33] M.-L. Ho, W.-H. Seto, L.-C. Wong, and T.-Y. Wong, "Effectiveness of multifaceted hand hygiene interventions in long-term care facilities in Hong Kong: a cluster-randomized controlled trial," Infection Control \& Hospital Epidemiology, vol. 33, no. 8, pp. 761-767, 2012.

[34] A. Huis, M. Hulscher, E. Adang, R. Grol, T. Van Achterberg, and L. Schoonhoven, "Cost-effectiveness of a team and leaders-directed strategy to improve nurses' adherence to hand hygiene guidelines: a cluster randomised trial," International Journal of Nursing Studies, vol. 50, no. 4, pp. 518-526, 2013.

[35] A. Huis, L. Schoonhoven, R. Grol et al., "Helping hands: a cluster randomised trial to evaluate the effectiveness of two different strategies for promoting hand hygiene in hospital nurses," Implementation Science, vol. 6, no. 1, p. 101, 2011.

[36] A. Huis, L. Schoonhoven, R. Grol, R. Donders, M. Hulscher, and T. van Achterberg, "Impact of a team and leaders-directed strategy to improve nurses' adherence to hand hygiene guidelines: a cluster randomised trial," International Journal of Nursing Studies, vol. 50, no. 4, pp. 464-474, 2013.

[37] M. M. Jansson, H. P. Syrjälä, P. P. Ohtonen, M. H. Meriläinen, H. A. Kyngäs, and T. I. Ala-Kokko, "Simulation education as a single intervention does not improve hand hygiene practices: a randomized controlled follow-up study," American Journal of Infection Control, vol. 44, no. 6, pp. 625-630, 2016.

[38] C. Martín-Madrazo, S. Soto-Díaz, A. Cañada-Dorado et al., "Cluster randomized trial to evaluate the effect of a multimodal hand hygiene improvement strategy in primary care," Infection Control \& Hospital Epidemiology, vol. 33, no. 7, pp. 681-688, 2012.

[39] D. Mertz, N. Dafoe, S. D. Walter, K. Brazil, and M. Loeb, "Effect of a multifaceted intervention on adherence to hand hygiene among healthcare workers: a cluster-randomized trial," Infection Control \& Hospital Epidemiology, vol. 31, no. 11, pp. 1170-1176, 2010.

[40] D. Santosaningsih, D. Erikawati, S. Santoso et al., "Intervening with healthcare workers' hand hygiene compliance, knowledge, and perception in a limited-resource hospital in Indonesia: a randomized controlled trial study," Antimicrobial Resistance \& Infection Control, vol. 6, no. 1, p. 23, 2017.

[41] A. J. Stewardson, H. Sax, A. Gayet-Ageron et al., "Enhanced performance feedback and patient participation to improve hand hygiene compliance of health-care workers in the setting of established multimodal promotion: a single-centre, cluster randomised controlled trial," The Lancet Infectious Diseases, vol. 16, no. 12, pp. 1345-1355, 2016.

[42] T. V. Lengerke, B. Lutze, C. Krauth, K. Lange, J. T. Stahmeyer, and I. F. Chaberny, "Promoting hand hygiene compliance: psygiene," Deutsches Aerzteblatt Online, vol. 114, no. 3, p. 29, 2017.

[43] P. Xiong, J. Zhang, X. Wang, T. L. Wu, and B. J. Hall, "Effects of a mixed media education intervention program on increasing knowledge, attitude, and compliance with standard precautions among nursing students: a randomized controlled trial," American Journal of Infection Control, vol. 45, no. 4, pp. 389-395, 2017.

[44] V. L. N. Schölmerich and I. Kawachi, "Translating the socioecological perspective into multilevel interventions," Health Education \& Behavior, vol. 43, no. 1, pp. 17-20, 2016.

[45] S. Naikoba and A. Hayward, "The effectiveness of interventions aimed at increasing handwashing in healthcare workersa systematic review," Journal of Hospital Infection, vol. 47, no. 3, pp. 173-180, 2001.

[46] R. Grol and M. Wensing, "Effective implementation: a model. Improving patient care: the implementation of change in clinical practice," Quality \& Safety in Health Care, vol. 41, p. $57,2005$.

[47] L. J. Conway, L. Riley, L. Saiman, B. Cohen, P. Alper, and E. L. Larson, "Implementation and impact of an automated group monitoring and feedback system to promote hand hygiene among health care personnel," The Joint Commission 
Journal on Quality and Patient Safety, vol. 40, no. 9, pp. 408-417, 2014.

[48] Á. Lehotsky, L. Szilágyi, T. Ferenci et al., "Quantitative impact of direct, personal feedback on hand hygiene technique," Journal of Hospital Infection, vol. 91, no. 1, pp. 81-84, 2015.

[49] V. Mbarika, E. Bagarukayo, V. Hingorani, S. Stokes, M. Kourouma, and C. Sankar, "A multi-experimental study on the use of multimedia instructional materials to teach technical subjects," Journal of STEM Education: Innovations and Research, vol. 11, no. 1, 2010.

[50] H.-K. Chun, K.-M. Kim, and H.-R. Park, "Effects of hand hygiene education and individual feedback on hand hygiene behaviour, MRSA acquisition rate and MRSA colonization pressure among intensive care unit nurses," International Journal of Nursing Practice, vol. 21, no. 6, pp. 709-715, 2015.

[51] B. B. Longest Jr, Health Program Management: From Development through Evaluation, John Wiley \& Sons, Hoboken, NJ, USA, 2014.

[52] M. Subirana, A. Long, J. Greenhalgh, and J. Firth, "A realist logic model of the links between nurse staffing and the outcomes of nursing," Journal of Research in Nursing, vol. 19, no. 1, pp. 8-23, 2014.

[53] S. K. Baxter, L. Blank, H. B. Woods, N. Payne, M. Rimmer, and E. Goyder, "Using logic model methods in systematic review synthesis: describing complex pathways in referral management interventions," BMC Medical Research Methodology, vol. 14, no. 1, pp. 1-9, 2014.

[54] P. D. Sherman, "Using RUFDATA to guide a logic model for a quality assurance process in an undergraduate university program," Evaluation and Program Planning, vol. 55, pp. 112-119, 2016.

[55] K. M. White, N. L. Jimmieson, P. L. Obst et al., "Using a theory of planned behaviour framework to explore hand hygiene beliefs at the " 5 critical moments" among Australian hospitalbased nurses," BMC Health Services Research, vol. 15, no. 1, pp. 1-9, 2015.

[56] M. Sharma, Theoretical Foundations of Health Education and Health Promotion, Jones \& Bartlett Publishers, Burlington, MA, USA, 2016.

[57] B. Cislaghi, E. K. Denny, M. Cissé et al., "Changing social norms: the importance of "organized diffusion" for scaling up community health promotion and women empowerment interventions," Prevention Science, vol. 20, no. 6, pp. 936-946, 2019.

[58] R. Dickie, S. Rasmussen, R. Cain, L. Williams, and W. MacKay, "The effects of perceived social norms on handwashing behaviour in students," Psychology, Health \& Medicine, vol. 23, no. 2, pp. 154-159, 2018.

[59] D. Batras, C. Duff, and B. J. Smith, "Organizational change theory: implications for health promotion practice," Health Promotion International, vol. 31, no. 1, pp. 231-241, 2016.

[60] J. L. Fitzpatrick: Program Evaluationalternative Approaches and Practical Guidelines 2011. 